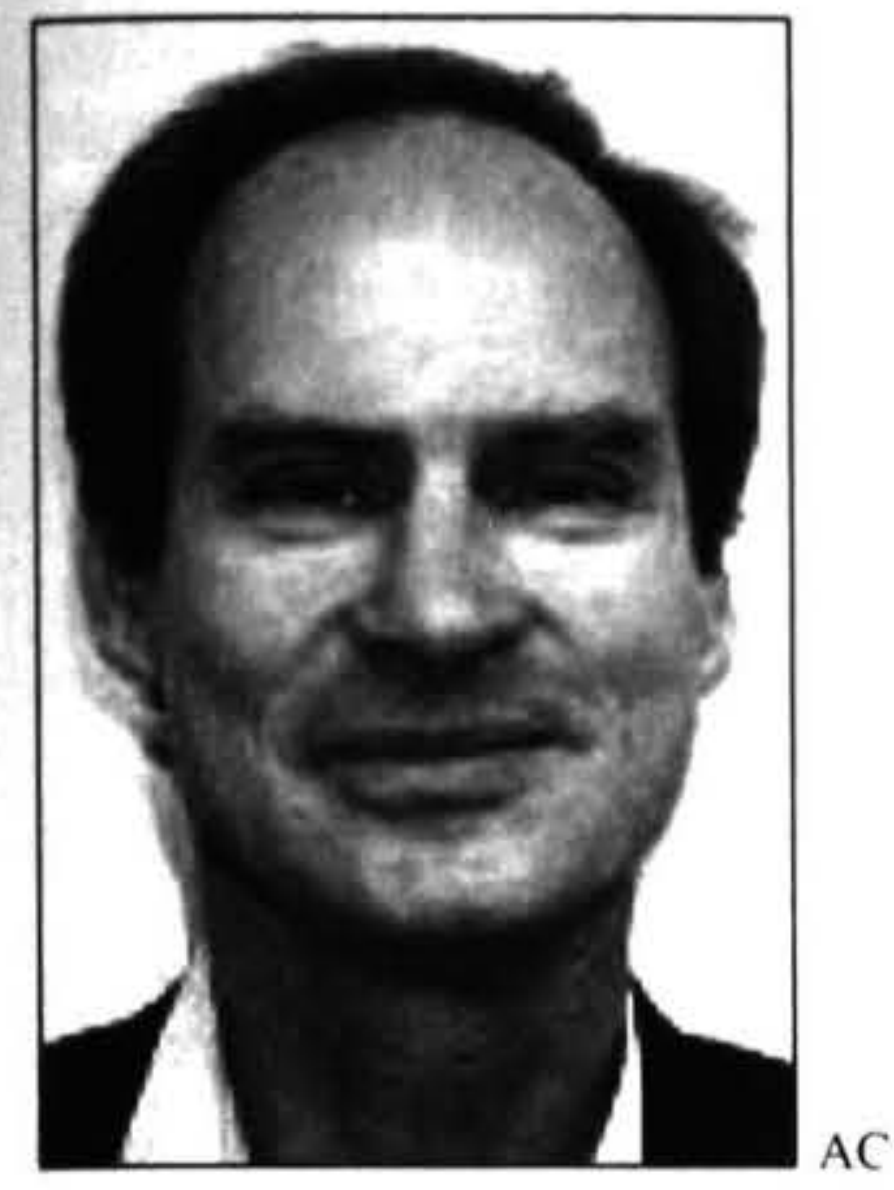

\title{
COMPLEMENTARITIES \\ BETWEEN RECRUITMENT AND SELECTION PRACTICES AND EMPLOYEE LEARNING IN NEW ZEALAND SMALL AND MEDIUM-SIZED ENTERPRISES
}

\author{
Alan Coetzer \\ Department of Management and Enterprise \\ Development. \\ Massey University, Wellington
}

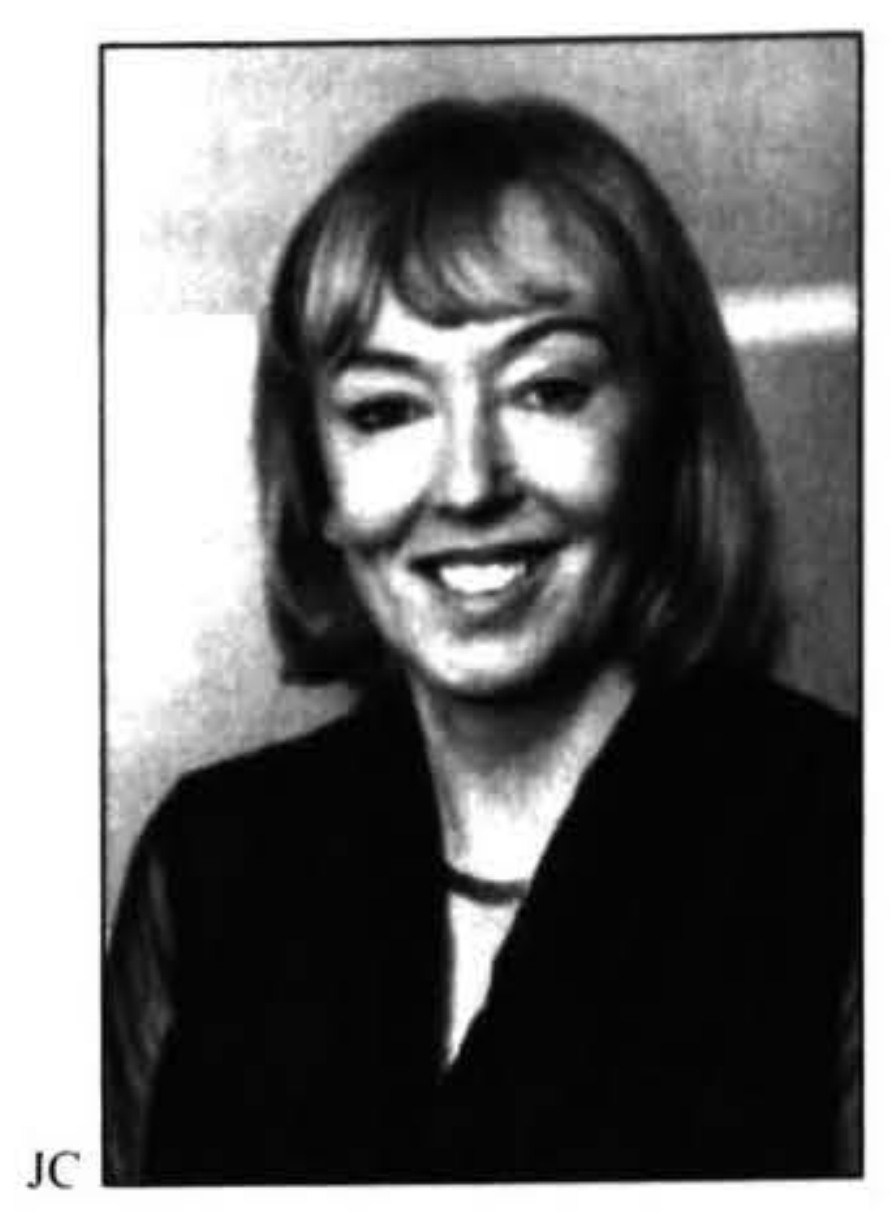

Jacqui Campbell

\author{
Department of Management and Enterprise \\ Development, \\ Massey University, Wellington
}

\begin{abstract}
As a response to comments by numerous authors about lack of attention given to small and medium-sized enterprises (SMEs) in human resource management (HRM) literature, this paper examines complementarities between recruitment and selection practices in SMEs and the work-related learning of newcomers. Data were collected through interviews with mainly owners/managers of 60 firms emploving up to 50 staff. Analysis of the interviews suggests that the recruitment and selection practices used by some owners/managers had unintended positive effects on newcomers learning. Trusted current employees were encouraged to recnit new staff from their networks of family and friends. Sponsors often took the initiative in supporting newcomers on their pathways of work-related learning. Also, some owners/managers used selection methods that involved candidates demonstrating their skills on-the-job, through work samples or work trials. These selection methods yield, as a by-product, information about candidates 'learning needs. Such information assists workplace models who guide learning io select tasks appropriate to the learner's level of development. The paper concludes that researchers should pay less attention to traditional HRM functions and start to focus on complementarities that might exist among HRM practices. Such a focus may be more consistent with the ways owners/managers vieu' managing human resources.
\end{abstract}

\section{Introduction}

For some time, the New Zealand government has been interested in specific ways in which it can assist SMEs to improve performance, build capability and increase their contribution to the economy. An example of one such major initiative is the regularly administered Business Practice and Performance Survey. The various iterations of this survey highlight areas of concern regarding human resource management (HRM) practices that reveal differences between 'leading' and 'lagging' firms, and indeed small and large firms. The 2001 Business Practice and Performance Survey (Knuckey et al. 2002) yielded the most extensive set of representative data on business capability in New Zealand. This study found that, on the whole, HRM practices were underdeveloped and HRM practices were an area of critical difference between the 'leading' and 'lagging' firms in this study. The results of this study also showed that there are differences between the HRM practices of small and large firms; small firms (defined in the study as firms employing 6-19.5 full-time equivalent staff) are less likely to demonstrate best practice in relation to their employees. In short, it seems that New Zealand small and medium enterprises (SMEs) are managing their human resources less effectively than is desirable.

SME owners/managers (hereafter referred to as managers) face many unique HRM challenges, such as difficulty in attracting and retaining talented employees (Cardon and Stevens, 2004; Williamson, 2000). Considering these human resource issues in the context of each individual firm renders them largely insignificant. However, when the SME sector as a whole is facing such human resource issues (as research has indicated) then the issue grows in both impact and significance.

Given the importance of the SME sector in New Zealand (Ministry of Economic Development, 2006), policy makers have been keen to design initiatives to address issues such as productivity and skill shortages in SMEs. Such initiatives, while well intentioned, are frequently not 
considered in the operating context of SMEs. This is largely because there is little research that has explicitly sought to investigate the nature of the HRM experiences of SME managers in a qualitative way. This is not surprising as the wider body of knowledge on human resource 'best practice' has been built from studying large firms (Cassell, Nadin, Gray, and Clegg, 2002).

As the ways in which the SME sector contributes to a country's economic and social goals has become more widely understood, there has been a growing emphasis on encouraging the managers of these enterprises to engage in 'best practice' initiatives. This in itself is, at this stage, a relatively ambitious goal, given that there is a lack of data and theory related to HRM practices in SMEs (Cardon and Stevens, 2004; Cassell et al. 2002), especially in the New Zealand context. Building upon these ideas, this paper examines recruitment, selection, and training practices in a sample of New Zealand SMEs, an SME being defined as a firm that employs 5-50 equivalent fulltime staff (EFTS).

\section{Background}

Several studies of HRM practices in SMEs have found that recruiting staff typically involves the use of methods that are convenient, inexpensive, and directly controllable by the firm (Cardon and Stevens, 2004). Such methods include personal referrals and referrals by trusted employees (word-of-mouth), unsolicited applicants, and advertisements in local community newspapers. For example, studies in SMEs by Kotey and Slade (2005) in Australia, and Cassell et al. (2002) in the United Kingdom, found that word-of-mouth was the main source of recruitment. Similarly, a survey of HRM practices in 408 small firms in Australia found that advertisements and referrals/ "walk-ins" were common methods of recruitment (Barrett and Mayson, 2005). The use of more formal recruitment sources, such as employment agencies and newspaper advertising. increases with firm size (Kotey and Slade, 2005). This is because of the need to widen the search for suitable employees as the pool of potential employees from sources such as family and friends becomes exhausted, and the skills required to support firm growth are not readily available from these informal sources

As with recruiting, there is strong evidence from the findings of several studies (Barrett and Mayson, 2005; Kotey and Slade, 2005) that managers have a preference towards a small number of employee selection methods. These studies indicate that the most preferred methods include informal interviews, work samples, and work trials. Kotey and Slade (2005) investigated the rate of adoption of formal HRM practices with increasing firm size. They found that the use of a wider variety of selection techniques, such as testing and reference checks. increased with firm size, probably because new recruits are more likely to come from outside the network of family and friends. This increases the costs of recruiting, the need for more in-depth screening, and potential risks in selection because applicants may not have been refierred.
Within the SME literature there has been an accumulation of knowledge on formal training practices. The research evidence has consistently shown that SMEs provide less formal training than larger firms (Patton, 2005). However, the extent to which there is a problem of limited training in SMEs may be related to definitions and measures of training that SME researchers commonly use (Kitching and Blackburn, 2002). The claim, often made in the SME literature, that training provision is positively correlated with firm size is based on a narrow definition of training. There seems to be increasing recognition amongst commentators that widening the definition of training activity to include less formal ways of workrelated learning may reduce the training gap between small and larger businesses. Related to this, there also appears to be wider recognition that comparing large and small firms' training practices with the same yardsticks (e.g. type of training, frequency of training, duration of training, cost of training) can be misleading. However, the reliance upon informal training within SMEs makes the documentation and analysis of such activity more problematic (Patton, 2005).

Our understanding of informal training practices and informal learning processes in SMEs has been underdeveloped. This can be attributed to a seemingly persistent focus of SME researchers on formal approaches to learning, and their apparent strong preference towards snapshot quantitative training practices surveys. However, there appears to be a growing awareness amongst commentators that the role and importance of informal training and informal learning processes in SMEs needs to be recognised (Billett, Hernon-Tinning, and Ehrich, 2003: Gibb, 1997). For instance, Kitching and Blackburn (2002) promote the suitability of more informal approach to training and identify the limited relevance, and disproportionate costs, of formal training approaches to SMEs.

\section{Method}

This paper is based on data from two separate studies. The first was a small-scale exploratory study that examined informal training practices and informal learning processes. Data for the exploratory study were collected from 17 people through semi-structured interviews that lasted 45 to 60 minutes. The interviewees were owners, employee managers, and non-managers in ten Wellington-based manufacturing firms that each employed 10 to 50 EFTS. The interviews were taperecorded and later transcribed.

The research aim of the second study was to develop an understanding of the basic HRM practices employed by managers in SMEs. Data were collected from managers of 50 well-established firms in urban and rural locations of New Zealand. Using a commercial database, a random sample of 500 firms employing 5 to 50 full-time equivalent staff in the manufacturing or services sectors was selected. The 50 participants were recruited from this sample frame. The managers were interviewed and taken through a semi-structured interview schedule which included questions designed to get interviewees to 
elaborate on the HRM practices that the firm employed. Each interview lasted 45 to 90 minutes and was taperecorded. The interviews were later transcribed.

For the purpose of developing this paper, the textual interview data from both studies were combined. Content analysis (Weber, 1985) was used to aid in classification of the textual interview data into three broad categories, namely, (1) recruitment, (2) selection, and (3) training. All phrases, sentences and paragraphs in the textual interview data were reviewed in relation to these three broad categories and then classified into the most appropriate category. The main tactics for drawing meaning from the data were teasing out themes or looking for 'recurring regularities' (Patton, 1990) in the data.

\section{Practices in the Sample Firms}

As seems to be the case with smaller firms, word-of mouth was the preferred method of recruitment.

\begin{abstract}
"It's a word-of-mouth sort of a thing: that's how we recruit people. Because we ve lived in the town for twenty years we ve got to know lots of people so we mav approach someone and ask them if they are looking for work. We definitely do not advertise in the newspaper. "
\end{abstract}

"Word-of-mouth is probably the only. recruitment I would ever use. It would be unusual to use advertising to find staff. because Invercargill is so small, everybody. knows everybody."

Generally the recruitment process entailed managers encouraging trusted staff to ask people within their networks of family and friends to work for them. As could be expected, this led to situations where many newcomers were from existing workers' familial and social milieu:
"A lot of the actual production line work. that's pretty well all done by ladies. There's a good mixture out there of different Island groups and Maori. A lot of the Island ones come from within a church group and there are about three members of one family out there. "

In fact, some managers allowed employees substantial autonomy in attracting new staff, and were thus ceding considerable discretion over staffing decisions.

"I haven't advertised for any production
staff for six years. When somebody leaves
the production staff find their own
replacements."

The findings suggest that staff who recruited newcomers from their networks of family and friends often took the initiative in the socialisation of the new recruits.

\begin{abstract}
"We've tended to hire family members in many cases. So, in our company of 20 staff. there are four families. There is obviously a bit of pre-employment training that goes on within the family. That has its challenges, but probably makes things a bit easier as well."
\end{abstract}

This comment suggests that some newcomers started the processes of being acculturated into the organisation and developing an understanding of requirements of the owners/managers, before commencing employment.

The following excerpt provides further support for the contention that significant familial involvement, which was encouraged in some of the firms studied, has important implications for newcomers' work-related learning. The supervisor's comments suggest that he gave his son extraordinary attention as a learner.

"I came home from work one night and he said. 'I'm leaving school'. And I said. 'No you 're not!' He said, 'Yeah. I'm leaving school: He said, 'I've got an apprenticeship.' So I thought, oh, okay. 'Where have you got this apprenticeship?' He said. 'Where you work'. So the system had been shortcut. I didn't get spoken to about it at all. But he served his time and he 's doing really well now. And I probably was harder on him than anybody else."

However, managers could also use such recruitment processes as a means of exerting indirect control over the workforce and shifting their overall responsibility for the initial socialisation, training, and job performance of newcomers to their staff.

\begin{abstract}
"The good thing about it is that if somebody is not doing the job properly you really don 't have to do much. They sort it out themselves. And I stay out of it. I just speak to Mareikura, who is the Union delegate. And we just don't have to worry about whether anyone's up to the job, because the rest keep them up to the job. Or you'll find that one will suddenly stop turning up. I'll say. 'She's not turning up'. and they say. 'No. she's left. but I've got another girl lined up'. "
\end{abstract}

People just applying for a job without any prompting from the firm (unsolicited applications), was another effective and low cost source from which firms commonly recruited potential employees.
"I favour the people that actually come looking for a job. I have advertised, but haven't had a lot of success. I seem to get on a lot better if somebody has rung up, or just walked in and wanted to do the job."

The use of word-of-mouth referrals and unsolicited applications clearly overshadowed the use of more formal 
and expensive recruitment sources, such as newspaper advertising, the internet, and personnel agencies in larger towns and the cities. Such formal sources were used almost exclusively when firms were trying to recruit either applicants with specialised skills, or applicants in areas of employment where there were shortages of skilled labour. When faced with such challenging labour market conditions, some managers resorted to poaching.

\section{"If we want experienced people we have to pursue them off another company. "}

Overall, managers expressed a strong preference towards informal, low cost recruitment processes. The effectiveness of such recruitment processes generally depends on factors such as the firm having a good reputation as an employer and the willingness of current employees to recruit staff from their familial and social milieu. Pre-selection, which is often an integral part of such recruitment processes, may simplify employee selection processes.

\section{Selection}

Many managers expressed reservations about the utility of interviews as an aid in the selection process. Instead, they preferred to find out exactly what candidates could and could not do by getting candidates to complete work samples.

\section{"If we had a welder come through here, I'd just say: 'You go and weld a pipe up.' I could tell within two mimutes whether he's a welder or not."}

"Ther hasically go and sit on a sewing machine and the operators tell us whether they can sew or not. That 's way better than me saring. 'I like this person'. Because if they can't sew, then they can't sew!."

Nevertheless, many managers did not seem overly concerned about the candidate's technical skills. They were more interested in the potential employee's impact on the existing workforce. Thus, person-organisation fit seemed to carry more weight than person-job fit. The selection interview, described by many managers as merely an informal dialogue, was used primarily to assess the applicant's fit with the workplace culture and ability to work in a team, especially where skills could be easily taught.

"At the time of the interview I spend a lot of time thinking how the person will gel into the organisation. not necessarily their technical ahilities hut will they fit. We have a statf of eleven people and vern: very low staff turnover: I consider my staff to be friends. In an organisation of this size personal disputes can be quite damaging and very hard to manage."
"Actually don't really ask much about work. To me it's more about attitude. We can teach anyone to glaze."

"I'm sort of interviewing them with the idea of how are they going to impact on the team. Are they going to fit in? Do I think they'll be trouble-makers? Marty's main interest is can they do the job well. He'll actually walk them through the shop and just judge their reactions to machinery and equipment that we've got, to see if they know what it is."

Hiring employees for a trial period and then closely monitoring their job performance was another common approach to assessing person-job and person-organisation fit.

\begin{abstract}
"Our main recruitment area is when we have major peaks of work we tend to bring on casual contract labour to help us through that peak. And we often pick the eyes out of those people that come in. They might be here for two to three months, and that's long enough to assess those sorts of people and their value to what we do."

"My interview with a lot of people that I employed would be no more than two minutes. 'Don't tell me how good you are. you've got one week to show me', that's all I would sav."
\end{abstract}

In addition to providing managers with the information they needed to make employee selection decisions, such selection methods also helped diagnose newcomers' current skills levels, and provided managers and other staff with information about the learning needs of new recruits. Workplace supervisors and experienced coworkers could then identify and select tasks appropriate to learners' levels of readiness and establish learning pathways for them.

"Usually we throw them in the deep end
and see how they swim. We did that with
Marcel and he did very well. He did some
very difficult tasks that usually require
quite a bit of training. and he was doing
them on his first day and in his first week.
So he was very skilled in picking up skills,
and doing it quickly. And then you just
gradually learn what his weaknesses and
his strengths are. And you apply what
would help his strengths and what would
help his weaknesses."

On the whole, managers did not assign much importance to traditional selection devices such as $\mathrm{CVs}$, references, and formal interviews. Instead, they preferred to conduct a practical assessment of applicants' technical skills through work samples or work trials and have an informal dialogue with applicants to determine person-organisation fit. Work samples and work trials also served as 
mechanisms to identify the learning needs of new recruits. Once learning needs were established, training could commence.

\section{Training}

On the whole, managers were reluctant to allow staff to engage in formal off-the-job training. Only a few managers reported significant staff engagement in such training. Their firms typically either employed apprentices who were required to attend formal off-thejob training, or their firms had strong affiliations to industry associations that sponsored training courses. Some staff attended courses offered by suppliers. However, most managers emphasised the suitability and benefits of a more informal approach to staff training, and identified limited relevance and disproportionate costs of formal training approaches. Formal off-the-job training was typically perceived as being de-contextualised from the specific problems and priorities of the business. Combining work and learning was the preferred mode of knowledge and skill acquisition.

\begin{abstract}
"You have to weigh up whether the course they go on is actually going to benefit them here, or are they going to be of more benefit to have staved here and be working and learning."
\end{abstract}

The arrival of new employees was an important learning trigger in the firms studied. Workplace cultures and practices determined learners' activities and shaped their learning.

"It's our own ways that we feel sets us aside from another company. They pick that up by us training them to do it that way. I say. 'Well I'm sorry. this is one procedure you might have to forget. This here will take the place of that'. So he does it our way."

The learning of new employees was primarily jobspecific, as opposed to general work-related learning. 'Learning-by-doing' was the dominant process of knowledge and skills acquisition. Interviewee descriptions of this process typically approximated the four processes of social learning theory (Bandura, 1977): attention, retention, motor reproduction, and motivational processes.

\footnotetext{
"Watch me, see how it's done. Let them have a go at it. Monitor it. Explain whether they're getting it right, or what they can do to make it easier for them. That's ongoing. "
}

Usually, managers, or other experienced employees, established pathways of learning activities for new employees that provided engagement in tasks of increasing accountability and complexity (Lave and Wenger, 1991). This usually involved having a procedure demonstrated by workplace models and newcomers repeating the procedure until they became proficient at it. Thereafter, these processes of interaction with more experienced co-workers continued. In this way novice employees were guided through the complexities of firms' practices and taught 'tricks of the trade' (Billett, 2001).

"If I was to give an employee a job that he hadn't done before, or a new employee work, the best option is to put him with somebody who has done the job before. In that way they can communicate with that person as to why they do these things, and the process in which they do them. And that may happen a couple of times and then that employee who is new would be put on that job by himself and then he would learn that way by doing it himself and also pick up the individual skills to do it, and come up with different ideas as to how it can be done better and more efficient as well. So that 's generally how employees learn, if it's a difficult task. We usually employ somebody who has got the practical skills to do some very basic tasks. So we give them some basic tasks straight away to see how they go. And that's the process of learning a skill."

"What we tend to do is try and pair guts up. So there is one guy, for example, who has been here for about five years, and he works virtually exclusively on the roller doors. One of the guys will say, 'I'm not doing enough roller doors:. So we will send him out with Peter for half a day: He's working with Peter who knows all about the roller doors. A lot of it is tricks that they pick up."

Although access to direct guidance from models was crucial to development of knowledge and skills, indirect guidance, such as learners listening to and observing other workers, was also considered important:

"But as far as training goes, it's watching others, it's watching Adam and other people. There's nothing formal about training or skill development."

Health and safety regulatory requirements were a key learning trigger in the sample firms. Learning safe work practices is important, especially in manufacturing firms. In some of the SMEs studied, new employees' workplace learning agendas clearly reflected management's responsibility to comply with health and safety regulatory requirements.

\section{"Actually health and safety is the very first thing we teach."}

Again, managers had a strong preference towards informal training practices. Such training was primarily 
directed at helping newcomers acquire job-specific knowledge and skills, and skills in safe-work practices. However, once new employees were proficient at their tasks, and some responsibility for health and safety had been transferred to the new employees, the emphasis on learning seemed to diminish.

Managers in some firms fostered ongoing learning through providing access to a range of work place activities

\begin{abstract}
"If we train fitters and turners we train them in every aspect. They do a stint on the automatics, and on the capstans, they also get involved on the presses. Then they get into the drafiing side, learning the shrinkages on dies. And they spend time in the tool room. So they can do a variety of jobs, they are tanght the whole lot right through."
\end{abstract}

"They may start simply hy cutting steel to the appropriate lengths, they mar or may. not set up the saw to do that. The next thing the mas be working on a drilling machine, lathe, or eventually they may show some aptitude and move through to welding.

"There is an element of multi-skilling that goes on. Some of them may work in our wire area. and hecome an acrlic worker. or an acrolic worker man hecome a sheetmetal worker. And they mar find that they are not coping with acrylic work. hut they get into sheet-metal and for some reason ther have an affinity for that department and they tend to stan there then.

Engagement in a wide range of workplace activities thus presented opportunities for employee learning in some firms. However, other workplaces were characterised by low skilled work, with low learning potential. In such workplaces some managers used job rotation to reduce boredom, as opposed to fostering learning.

\section{Discussion}

The findings presented here in regard to recruitment and selection practices in the sample SMEs are largely consistent with previous research (Cassell et al., 2002; Kotey and Slade, 2005). The findings suggest most managers relied heavily on convenient and inexpensive sources of recruitment, such as the family and friends of current staff (Cardon and Stevens, 2004; Kotey and Slade, 2005: Marlow, 2000). While there are limitations associated with this approach to recruitment, given the time and financial resource constraints under which most SMEs operate (Cassell et al., 2002), it could be argued that the benefits of such an approach outweighs the limitations. Thus, the recruitment practices seemed, for the most part, to reflect the limited resources as well as the shorter lines of communication and community embeddedness of SMEs.

The widespread use of word-of-mouth referrals as a recruitment method simplifies employee selection processes in these firms. As Kotey and Slade (2005) have noted, the use of referrals as a recruitment method reduces the need for in-depth screening. In fact, in the firms studied there appeared to be little screening for particular technical skills, presumably because these could be easily learnt. Instead, managers seemed to consider general 'fit' as a key employee selection criterion. This finding, that the focus was on general fit, not specific job requirements, is consistent with previous research (Cardon and Stevens, 2004). Similarly, Marlow (2000) has argued that, "where a workforce is small and likely to be working in close proximity, the benefits of choosing a new employee who 'fits' outweighs the potential costs of employing someone who, however well qualified, does not fit." Thus, sustaining group cohesion seemed to be an important decision-making objective in the employee selection decision-making processes of SME owners/managers.

Overall, the findings in relation to training support the contention that SME managers have a strong preference towards informal training practices (Billett et al., 2003). Such training was primarily directed at helping newcomers acquire job-specific knowledge and skills and safe-work practices. The training process typically involved a workplace supervisor or experienced coworker demonstrating key behaviours to replicate, and providing the newcomer with both opportunities to practise and feedback on the practise performance. Thus, workplace supervisors and co-workers were important resources for learning. Once newcomers were proficient at their tasks, the emphasis on learning diminished. Further employee learning was almost exclusively triggered by work-related problems. In some firms job rotation, new tasks, or new work methods made important contributions to employee learning.

Analysis of the data supports Cardon and Stevens' (2004) contention that researchers need to explore complementarities among HRM practices in SMEs in greater depth. Recruitment and selection practices had unintended effects on employees' work-related learning. Specifically, some managers encouraged trusted staff to recruit new employees from their family and friends. The findings suggest that when existing staff are involved in recruiting newcomers from their family and friends, they are also likely to take the initiative in supporting these newcomers on their pathways of work-related learning. Also, in many firms applicants had to complete work samples to demonstrate their ability to do the job. The findings suggest that such employee selection methods are likely to yield, as a by-product, information about candidates' learning needs. Such information can assist those who will guide their learning to select tasks appropriate to the learner's level of development. 


\section{Limitations}

The findings presented here may be prone to social desirability bias (Zikmund, 2003) because labour employment practice is potentially sensitive. Consequently, some participants may have responded in a way intended to create a favourable impression of their HRM practices. The use of primarily a single-source (the owner/manager) is another limitation (Donaldson and Grant-Vallone, 2002). In the firms studied, managers and employees will understandably have different perceptions of HRM practices. Obtaining employee perspectives on practices is important. As research shows, employee perceptions of HRM practices are positively related to customer evaluations of service quality (Gelade and Young, 2005). Thus, future research should obtain employee perspectives on HRM practices in SMEs.

\section{Conclusion}

The findings presented here make a contribution to an understanding of important HRM practices in SMEs. The findings highlight informal training practices and informal learning processes in SMEs. Overall, the findings suggest that formal training approaches to processes of knowledge and skills acquisition are minimal in relation to the contributions made by informal interactions with workplace supervisors and co-workers, and 'natural' learning processes, such as learning through observation.

\section{Future Research}

More empirical studies are needed to further enhance understanding of informal training practices and informal learning processes in SMEs. In such future work, insights from situated learning (Lave and Wenger, 1991), informal and incidental learning (Watkins and Marsick, 1992) and social learning (Bandura, 1977) may be especially helpful in arriving at a better understanding of the research topic.

The findings also contribute data on complementarities among practices. Cardon and Stevens (2004) have argued that there is a need for field research that explores the interaction of HRM practices in SMEs. They also urged scholars to develop systems of practices that create synergistic effects, as opposed to independent sets of best practices. Complementarities were found among the practices used by some firms in the sample. In some firms the recruitment, selection, and training practices appeared to be operating synergistically. The SME research community should seek to better understand these and other potentially synergistic HRM practices.

\section{References}

Bandura, A. (1977). Social Learning Theory. Englewood Cliffs, NJ: Prentice-Hall.

Barrett, R., and Mayson, S. (2005). Getting and Keeping Good Staff: HR Issues and Challenges in Small Firms. Melbourne: CPA Australia.
Billett, S. (2001). Knowing in practice: Reconceptualising vocational expertise. Learning and Instruction, 11(1), 431-452.

Billett, S., Hernon-Tinning, B., and Ehrich, L. (2003). Small business pedagogic practices. Journal of Vocational Education and Training, 55(2), 149167.

Cardon, M.S., and Stevens, C.E. (2004). Managing human resources in small organizations: What do we know? Human Resource Management Review. 14, 295-323.

Cassell, C., Nadin, S., Gray, M., and Clegg, C. (2002). Exploring human resource management practices in small and medium sized enterprises. Personnel Review, 31(6), 671-692.

Donaldson, S.I., and Grant-Vallone, E.J. (2002). Understanding self-report bias in organizational behavior research. Journal of Business and Psychologv, 17(2), 245-260.

Gelade, G.A., and Young, S. (2005). Test of a service profit chain model in the retail banking sector. Journal of Occupational and Organizational Psychologv, 78, 1-22.

Gibb, A.A. (1997). Small firms' training and competitiveness. Building upon small business as a learning organisation. International Small Business Journal, 15(3), 13-29.

Kitching, J., and Blackburn, R.A. (2002). The Nature of Training and Motivation to Train in Small Firms. London: Small Business Research Centre, Kingston University.

Knuckey, S., Johnston, H., Campbell-Hunt, C., Carlaw, K., Corbett, L., and Massey, C. (2002). Firm Foundations: A Study of New Zealand Business Practices and Performance. Wellington, New Zealand: Ministry of Economic Development.

Kotey, B., and Slade, P. (2005). Formal human resource management in small growing firms. Journal of Small Business Management, 43(1), 16-40.

Lave, J., and Wenger, E. (1991). Situated Learning: Legitimate Peripheral Participation. Cambridge: Cambridge University Press.

Marlow, S. (2000). Investigating the use of emergent strategic human resource management activity in the small firm. Journal of Small Business and Enterprise Development, 7(2), 135-148.

Ministry of Economic Development. (2006). SMEs in New Zealand: Structure and Dynamics - 2006. Retrieved 4 July, 2006, online: http://www.med.govt.nz 
Patton, D. (2005). Training in smaller firms. In Marlow, S., Patton, D. and Ram, M. (Eds.), Managing Labour in Small Firms. London: Routledge.

Patton, M.Q. (1990). Qualitative Evaluation and Research Methods. (2nd ed.). California: Sage Publications.

Watkins, K.E., and Marsick, V.J. (1992). Towards a theory of informal and incidental learning in organisations. International Journal of Lifelong Education, 11(4), 287-300.

Weber, R.P. (1985). Basic Content Analysis. California: Sage Publications.

Williamson, I.O. (2000). Employer legitimacy and recruitment success in small businesses. Entrepreneurship Theory and Practice, 27-42.

Zikmund, W. G. (2003). Business Research Methods. Mason, Ohio: Thomson/South Western.

\section{Authors}

Alan Coetzer

Senior Lecturer

Department of Management and Enterprise Development Massey University

Private Bag 756

Wellington

A.J.Coetzer@massey.ac.nz

Jacqui Campbell

Lecturer

Department of Management and Enterprise Development Massey University

Private Bag 756

Wellington

J.A.Campbell@massey.ac.nz 